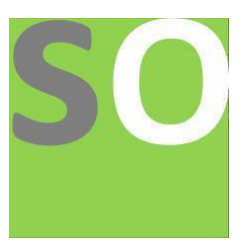

Article title: The Life of a Face Mask: from Production to Use to Disposal

Authors: Emily He[1], Esther Koh[2], Mythri Ambatipudi[3], DaLoria Boone[4], Paola Carrillo Gonzalez[5], Jordan Daigle[6], Taisa Kulyk[7], Kazi Tasnim[8], David Mooney[9]

Affiliations: John A. Paulson School of Engineering and Applied Sciences, Harvard University, Cambridge, MA, USA[1] Orcid ids: 0000-0002-1551-1503[1], 0000-0001-8542-888X[2], 0000-0002-7460-7492[3], 0000-0002-7460-7492[9] Contact e-mail: emily_he@college.harvard.edu License information: This work has been published open access under Creative Commons Attribution License http://creativecommons.org/licenses/by/4.0/, which permits unrestricted use, distribution, and reproduction in any medium, provided the original work is properly cited. Conditions, terms of use and publishing policy can be found at https://www.scienceopen.com/.

Preprint statement: This article is a preprint and has not been peer-reviewed, under consideration and submitted to ScienceOpen Preprints for open peer review.

DOI: 10.14293/S2199-1006.1.SOR-.PPA4GRK.v1

Preprint first posted online: 23 June 2021

Keywords: COVID-19, SARS-CoV-2, masks, filtration, decontamination, environmental impact 


\title{
The Life of a Face Mask: from Production to Use to Disposal
}

\author{
Authors \\ Emily M. He ${ }^{\mathrm{a}, \mathrm{b} \dagger}$, Esther Koh ${ }^{\mathrm{a}, \mathrm{b} \dagger}$, Mythri Ambatipudi ${ }^{\mathrm{a}, \mathrm{b}, \downarrow}$, DaLoria L. Boone ${ }^{\mathrm{a}, \mathrm{b}, \$}$, Paola Carrillo

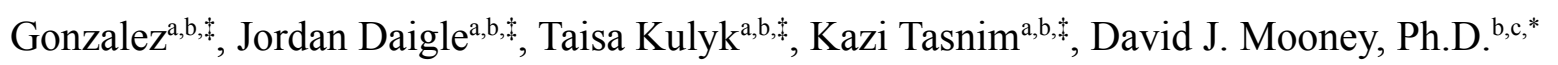

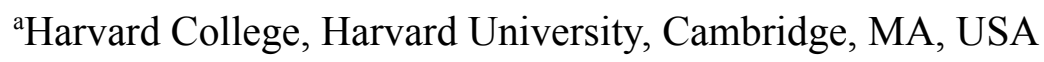 \\ bJohn A. Paulson School of Engineering and Applied Sciences, Harvard University, Cambridge, \\ MA, USA \\ ${ }^{\mathrm{c}}$ Wyss Institute for Biologically Inspired Engineering, Harvard University, Cambridge, MA, USA \\ †These authors contributed equally to this work. \\ *These authors contributed equally to this work. \\ *Corresponding author. Email: mooneyd@seas.harvard.edu, Phone: +1 (617) 495-1689, \\ Address: Pierce Hall 319, 29 Oxford St, Cambridge, Massachusetts, USA.
}




\begin{abstract}
Face mask usage is a critical means of limiting SARS-CoV-2 airborne transmission. To the best of our knowledge, a single study reviewing all major life stages of a mask has yet to be conducted. Here, we first describe the production and material sourcing of respirators, surgical/procedural masks, and cloth masks. We then evaluate filtration efficiency, fit, and breathability in estimating emitted viral load and personal compliance. In decontamination, vaporous hydrogen peroxide and ultraviolet germicidal irradiation are feasible and effective methods for large healthcare systems, while washing is recommended for masks with no electrostatic charge (e.g., cotton masks). Finally, we discuss how disposal of masks only contributes marginally to current environmental issues. Insights into the life cycle stages of masks may inform mask use and support mitigation strategies in preventing the spread of respiratory diseases.
\end{abstract}

\title{
Keywords
}

COVID-19, SARS-CoV-2, masks, filtration, decontamination, environmental impact

\section{Introduction}

Since its emergence, severe acute respiratory syndrome coronavirus 2 (SARS-CoV-2) has spread around the world, resulting in the World Health Organization's (WHO) declaration of a global pandemic. One of the most effective methods to limit SARS-CoV-2 airborne transmission is face mask usage [1].

Given their significant protective effect and high demand by healthcare systems, there have been shortages of N95 respirators and surgical masks since the COVID-19 outbreak [2]. To maximize existing resources, healthcare systems have adopted extended use strategies and decontamination methods, e.g., vaporized hydrogen peroxide treatment and ultraviolet germicidal irradiation [3,4]. In addition, the Centers for Disease Control and Prevention (CDC) has recommended the general public wear cloth masks [1]. When choosing which cloth mask to wear, the general public may consider factors such as filtration efficacy, cost and environmental impact of a mask, or even consider not wearing masks, citing comfort and personal autonomy concerns [5]. 
With face masks playing a critical role in reducing SARS-CoV-2 transmission, we provide an overview of the production, use, and environmental impact of N95 respirators, surgical/procedural masks, and cloth masks. We begin with a supply chain analysis, then proceed to evaluate the efficiency of various masks, review various decontamination methods, mask wearing compliance, and masks' environmental impact. The review concludes with a description of current limitations in evaluating masks and directions for further research.

\section{Material Sourcing and Production}

Generally, face masks can be grouped into three categories: respirators, surgical/procedural masks, and cloth masks (Figure 1). Face masks should be worn over a user's nose and mouth, serving as a barrier and filter from the surroundings. Cloth masks use mechanical filtration, whereas respirators and surgical masks additionally utilize electrostatic filtration, increasing their filtration efficiency [8]. Surgical and procedural masks are similar-both are made from flexible materials_-but only surgical masks are approved by the Food and Drugs Administration for medical use [9]. Respirators must meet stricter standards for filtration efficiency and are designed to provide a seal to the wearer's face [8].

Respirators, procedural, and surgical masks have similar production stages and component materials. They are manufactured from synthetic polymers, most commonly polypropylene, due to its dielectric properties, processing ease and low cost [9]. Masks are comprised of various filter layers. Surgical and procedural masks typically have three distinct layers [10] (Figure 1). The inner layer closest to the mouth of the user is usually made of spunbond polypropylene, which absorbs moisture from exhalation [11]. The middle layer, a meltblown nonwoven fabric, is the primary filtering mechanism [12]. The outer hydrophobic layer prevents fluids from penetrating the mask [11]. Respirators typically consist of four layers of filters that parallel a surgical mask, with an additional middle layer providing support for the frame [9] (Figure 1). Generally, the filtering middle layer is meltblown: a process by which microfibers and nanofibers of polypropylene are extruded and entangled, producing electrostatically charged media that can attract and trap aerosol particles [9,12]. Among cloth face masks, a wide variety of designs and 
materials are used. More filtration-effective cloth masks typically consist of a breathable hydrophilic material (e.g., cotton, silk or chiffon) and a hydrophobic material (e.g., polyester) that helps block secretions from entering and exiting a mask. Face masks also usually include a nose strip and elastic bands or fabric ties to secure the mask to the wearer's face and decrease leakage.

Given the wide range in costs of masks, does a more expensive mask mean increased filtration efficacy? We find that the cost versus filtration efficiency for different particle sizes of several types of masks that are currently on the market and/or in development do not demonstrate any simple correlation (Table A.1). Many hybrid masks are not mass-produced and their prices likely reflect the variability in production quantity, while surgical/procedural masks and respirators are typically manufactured in large volumes.

\section{Mask Use}

\subsection{Filtration Efficiency \& Fit}

Several studies have analyzed face masks' filtration efficacies and fits. Here, we describe which masks have high filtration efficacies and its contributing factors.

The particulate filtration efficiency of a mask, both while inhaling and exhaling, is calculated as:

$$
E=100\left(1-M_{d} / M_{u}\right)
$$

where $M_{d}$ is the particle count in downstream filtrate (air emerging from the mask) and $M_{u}$ is the particle count in upstream feed (air entering the mask) [14]. Bacterial and viral filtration efficacies, are both determined through the same method and are calculated as:

$$
B F E=100((C-F) / C)
$$

where $C$ is the number of bacterial colonies when no filter is used and $F$ is the number of colonies after the filter is used [14].

Using such calculations, mask efficacy against SARS-CoV-2 transmission can be assessed. Studies have consistently shown that N95 respirators are highly effective, up to $99.9 \%$, in 
filtering particles of sizes $\geq 0.3$ microns [13,15-17]. National Institute for Occupational Safety and Health (NIOSH)-approved respirators must filter at least $95 \%$ of such particles [1]. Other mask types demonstrate greater variability. For example, while certain publications report a surgical mask filtration efficiency of 97-99.6\% [13,16] (Figure 2), others report a range from $37-70 \%[15,17]$. Barrier face coverings are required by American Society for Testing and Materials (ASTM) to demonstrate filtration efficiency $\geq 20 \%$ for Level 1 protection and $\geq 50 \%$ for Level 2 protection [18]. Greater variability exists for cotton masks, with filtration efficiencies ranging from $14 \%$ to $99.5 \%$. [13] (Figure 2).

Several key factors influence mask filtration efficiency. As mentioned in Material Sourcing and Production, many masks, especially polypropylene-based masks, rely on two filtration mechanisms: (1) physical trapping through mechanical filtration and (2) attraction and trapping through electrostatic interactions [19]. Therefore, materials that both provide strong electrostatic properties and a mechanical barrier (e.g., N95, surgical masks) have high filtration efficiencies [13]. The number of filtering layers is another important factor, particularly for cloth masks that primarily utilize mechanical filtration. Multilayered cloth masks can have high filtration efficiencies, but with fewer layers used, they are less effective [13] (Figure 2). Additionally, a positive relationship between thread count and filtration efficiency has been observed $[13,17]$ (Figure 2).

Mask fit is also influential in affecting overall filtration efficacy by impacting the seal between the mask and the wearer's face. Surgical masks have a looser fit than respirators and therefore typically have significantly lower filtration efficiencies between 37-69\% [14]. Filtration efficiencies of several masks were measured after a gap was introduced [13]. Many masks with high filtration efficiencies under "no gap" conditions, i.e. good fit, demonstrated poorer filtration with gaps [13] (Figure 2). Even with highly effective filter materials, $10-40 \%$ of particles are still emerging from surgical masks with poor fit [20].

To quantify the impact of a mask in mitigating transmission, we performed an estimation of the viral load emitted when wearing no mask and 6 different types of masks under no gap conditions 
(Eq. A) [13]. The average tidal volume (i.e., volume of air in each breath) and number of breaths per minute were assumed to be $500 \mathrm{~mL}$ [21] and 14 respectively [22]. The average SARS-CoV-2 viral load emitted is as high as 0.637 copies $/ \mathrm{cm}^{3}$ when not wearing a mask [23] but is substantially reduced by wearing one with high filtration efficiency (Figure 3).

\subsection{Tradeoff Between Filtration Efficiency and Breathability}

While face mask filtration efficiency and fit are key to preventing disease transmission, breathability significantly impacts ease of use. Breathability describes a fabric's level of ventilation and the user's ease of breathing while wearing a mask of that fabric [24-25]. In order to provide a breathable micro-climate inside a mask, air, water vapor, and heat should be easily transferred out into the environment. A poorly ventilated mask may require greater effort to breathe, leading to damp and uncomfortable conditions inside the mask and reducing compliance of the wearer [24].

The pressure differential across a mask during air flow plays a vital role in its breathability. A low pressure drop indicates ease of air transport and high breathability [18]. The ASTM F3502 standard for the maximum pressure differential of barrier face coverings is 1.56 Pascals $(\mathrm{Pa})$ at 85 liters/minute. Masks with pressure differentials of $0.52 \mathrm{~Pa}$ or less are considered higher performing. Although both quilter's cotton 1 layer and flannel have desirable low-pressure differentials, they have very poor filtration efficiencies (Figure 2) [13]. Surgical masks and cotton masks with greater TPI (threads per inch) and greater number of layers have high filtration efficiencies but also higher pressure differentials [24]. Thus, a tradeoff between pressure differential and filtration efficiency occurs in these masks. However, N95 respirators appear to achieve a good balance between pressure differential and filtration.

Masks with distinct pressure differentials require differing efforts from users to breath. To quantify these effects, we can calculate the volumetric air flow rate that must be generated on the high pressure side of the mask (i.e., inside the mask for exhaling; outside the mask for inhaling) to accomplish the transport of a set amount of air across the mask. Using Poiseuille's Law, the required air flow rates through different masks were calculated using pressure differentials from 
the literature (Figure 4). To transport a given volume of air, a lower air flow rate is needed in masks that have low pressure differentials (e.g., N95, quilter's cotton 1 layer, and flannel), meaning the wearer would not have to breathe as hard.

Altogether, data from the literature and analysis performed here indicate that high filtration efficiencies may come at a cost of high air flow resistance. N95 respirators achieve a good balance between high filtration efficiency and low pressure differential. In contrast, one layer cotton masks have low-pressure differentials and high breathability but poor filtration efficiency. Design changes aimed to improve filtration in cloth masks, such as adding more layers and a greater thread count per area, may significantly impede breathability.

\subsection{Decontamination}

While many masks are designed for one-time-use, their limited supplies in the pandemic [2] have led governmental agencies to recommend decontamination as part of a reuse approach [1]. Analysis on the decay rate in respirator filtration efficacy supports this notion [27]. However, manufacturers do not recommend decontamination [28]. There are three main factors to consider with decontamination methods: ability to 1) reduce pathogen burden, 2) not harm mask filtration efficacy or fit, and 3) present no residual chemical hazard [1]. Three promising methods identified by NIOSH are described below.

\subsubsection{Vaporous Hydrogen Peroxide (VHP)}

Vaporous hydrogen peroxide (VHP) is produced through generators that micro-condense hydrogen peroxide to achieve a 6-log reduction in organism viability [3]. Four technologies utilizing VHP have received emergency use authorization (EUA) from the FDA (Table A.2). Advantages of VHP include its decontamination efficacy, high throughput, and low toxicity. Masks may undergo up to 20 decontamination cycles, with each cycle ranging from 30 minutes to 3 hours. Each cycle is capable of decontaminating tens of thousands of filtering facepiece respirators (FFRs) [28]. However, due to its large throughput and prohibitive cost, it may not be a viable decontamination method for communities outside of large healthcare systems $[3,4]$. 


\subsubsection{Ultraviolet Germicidal Irradiation (UVGI)}

UVGI uses the germicidal-spectrum in ultraviolet-C (UV-C) to decontaminate exposed surfaces. UV-C effectiveness is affected by the topography of targeted surfaces, location of viral particles, and mask placement [29]. A dose of 1-2 Joules/centimeter ${ }^{2}$ can achieve a $>4.79$ log reduction in viral load [28], and does not lead to significant filtration efficiency decay in N95 respirators, surgical masks, and procedural masks, supporting the current consensus that UVGI can decontaminate respirators for up to 10 cycles [30]. As decontamination cycles are short enough to potentially allow high throughput [28], UVGI is a feasible alternative to VHP. The CDC has approved a pilot UVGI system, which utilizes a transportable UV-C disinfection system previously shown to be effective in disinfecting hospital surfaces [29,31]. More affordable UVGI treatment systems with UV-C bulbs that fit into existing light fixtures have also been designed [4].

\subsubsection{Heat}

Heat is the most viable decontamination option in households due to its simplicity and availability. Dry heat at $70^{\circ} \mathrm{C}$ for 60 minutes results in a 3.3-log reduction in viral load [32]. Most ovens have a lowest temperature setting of $77^{\circ} \mathrm{C}$, and 30 -minute cycles at this temperature do not significantly degrade filtration efficiencies of N95 respirators, surgical, and procedural masks [30]. Moist heat has been suggested to better inactivate viruses than dry heat [33]. One of two methods of steam sterilization granted an EUA by the FDA is supported by 3M's filtration and fit tests [28]. Other methods recommend moist heat with temperatures of $70-85^{\circ} \mathrm{C}$ and relative humidity of $50-85 \%[32,33]$. Possible supersaturation of water may lead to loss of electrostatic charges and therefore degradation of filtration efficacy [30], but for masks without electrostatic charges, e.g., cloth masks, there is no limit to water saturation. In fact, the CDC and ASTM recommends cloth masks be laundered daily with other clothing according to manufacturer specifications $[1,18]$.

\subsection{User Compliance}

While public mask usage in the United States has increased since early 2020, differences exist in mask compliance among different demographic groups and geographical locations (Figure 5a) 
[36,37]. Caucasians, low income, and younger Americans are less likely to wear masks [38]. The Upper Midwest of the United States has the lowest mask compliance, while the Northeast and Westcoast have the highest compliance, with all states in these regions above 90\% (Figure 5a) [34]. While mask usage varies across the globe, most countries are recommending increased public mask usage (Figure 5b) [35]. There is a correlation between each country's increase in public mask usage, the total number of people infected, and the mortality rate due to the virus [35]. Even so, some countries in Africa which have maintained a low mortality rate [39], still instituted mandates to increase public mask usage (Figure 5b). Additionally, a research survey performed in Bangladesh found a significant relationship between the amount of fear reported and public mask usage [40]. Thus, public mask usage seems to not depend solely on COVID-19 cases and mortality, but also on fear of contracting SARS-CoV-2 among citizens.

Universal masking could be essential in controlling viral transmission, but poor compliance in the United States would undermine its efficacy. Self-reported public masking in the United States has varied from approximately 65-90\% since August 2020 [36,37]. Misconceptions may contribute to this $10-35 \%$ non-compliance, including insufficient knowledge regarding correct mask use, fears of mask $\mathrm{CO}_{2}$ build-up, concerns regarding cloth masks efficacy, and notions that masks are not needed if previously infected with the virus [41]. Noncompliance has also been attributed to mask discomfort (e.g., acne, itching, irritation, heat accumulation, light-headedness, shortness of breath), political ideology and personal autonomy concerns. [5]. Eliminating mask misconceptions and discomfort may help increase overall public mask compliance.

Despite self-reported mask usage remaining above $65 \%$ in the United States since August 2020, the number of COVID-19 cases began surging in mid-September 2020 [36,37]. The surge may be due to colder weather increasing indoor sheltering by individuals. In addition, hand washing negligence after removing masks for those that have come in contact with SARS-CoV-2 and improper disinfection of the mask after removal, may result in increased transmission and infection risks. Proper hygiene practices may increase the benefit of universal masking in reducing viral spread. 


\section{Environmental Impacts}

The surge in mask usage to combat SARS-CoV-2 transmission has prompted research on the environmental impact of masks. Numerous elements can be considered, such as microplastics $[10,12]$, carbon footprints of personal protective equipment (PPE) [42], and the prospect of biodegradable masks [11]. One study took a more comprehensive approach by examining four metrics: carbon footprint, non-renewable cumulative energy demand, water depletion according to the AWARE methodology (hereafter water footprint), and overall environmental impacts [43]. We provide a comprehensive environmental impact analysis of a broader range of masks while considering disposal methods and microplastics.

\subsection{Carbon Footprint}

Production, transportation, and disposal of face masks produce greenhouse gases. The carbon footprint of a mask is the cumulative greenhouse gas emissions over its lifecycle. The carbon footprint of a cotton mask and surgical mask is $0.23 \mathrm{~kg} \mathrm{CO}_{2}$-eq and $0.24 \mathrm{~kg} \mathrm{CO}_{2}$-eq respectively [43], which are low compared to other common emission sources such as driving a car or residential heating. The average passenger vehicle emits about $0.404 \mathrm{~kg}$ of $\mathrm{CO}_{2}$ per mile [44]. One surgical mask contributes $\mathrm{CO}_{2}$ emissions equivalent to driving approximately 0.6 miles. Disposing a surgical mask daily for a year would generate $87.6 \mathrm{~kg} \mathrm{CO}_{2}$-eq, leading to a $0.60 \%$ increase in an American's carbon footprint given that the average American's annual carbon footprint is 16 tons [45].

\subsection{Water Footprint}

The water footprint of face masks is important considering that water depletion and pollution threaten Earth's freshwater resources [46]. The average American's annual water footprint is $2,840 \mathrm{~m}^{3}$ [47], while the water footprint per cotton and surgical mask is approximately $3.5 \mathrm{~m}^{3}$ water-eq and $0.07 \mathrm{~m}^{3}$ water-eq respectively [43]. The water impact of both mostly comes from production; washing of the cotton masks plays a minor role in the overall water consumption [43]. Disposing one cotton mask in a year would increase an American's water footprint by $0.12 \%$ while disposing 365 surgical masks in a year would increase the water footprint by $0.9 \%$. 


\subsection{Disposal}

The disposal method of a mask (e.g., incineration, landfilling) affects how the environment is impacted. Schmutz et al. (2020) assumed incineration of masks at the end of their use, a valid assumption for densely populated countries [43]. However, only $11.1 \%$ of worldwide municipal solid waste (MSW) is incinerated [48]. Polypropylene incineration represents $36 \%$ of the disposable mask's carbon footprint, so other disposal methods could significantly alter the carbon footprint calculated [43]. Disposable masks are difficult to recycle and they are not biodegradable [11]. Over one year, the use of one respirator per day per healthcare worker would require 6.58 billion respirators, generating 74.4 million $\mathrm{kg}$ of waste [49]. The United States generated 265.3 billion $\mathrm{kg}$ of MSW in 2018 [44], so respirator waste from healthcare workers represents $0.028 \%$ of annual MSW.

\subsection{Microplastics}

The lack of mask recycling and prevalence of mask littering gives rise to significant concern that waste from mask material will persist in the environment [43]. Face mask material in water consumed by aquatic organisms could propagate through the food chain and create chronic health problems in humans [10]. The degradation of face mask material into microplastics is also a significant concern. Under certain conditions, littered or landfilled disposable face masks can fragment into particles under $5 \mathrm{~mm}$ in size [12]. Though microplastic pollution from face masks is not well understood [10], consequences of microplastics have been documented in scientific literature [10]. Microplastics also adsorb toxics, which can poison organisms [11]. Plastic particles have also been shown to cultivate pathogens, which could lead to more disease outbreaks [12].

\section{Conclusion}

Face mask usage is key in mitigating SARS-CoV-2 airborne transmission. Respirator and surgical/procedural mask filter media production is highly specialized and requires high initial investment, limiting its manufacturing. Thus, respirators and surgical masks are currently prioritized for healthcare workers. Filtration efficiency and fit are both critical features that control the viral load emitted by infected individuals and inhaled by healthy individuals. 
Breathability is another critical factor in mask design. In the event of mask shortage, VHP and UVGI are effective decontamination methods that enable mask reuse, but typically are only feasible in large healthcare systems. Therefore, community members may choose to wear masks with no electrostatic charge that can be decontaminated through washing. Since masks are an effective mitigation strategy, properly informing the public on the value of masks could encourage widespread public mask usage. While both disposable and reusable masks have been shown to impact the environment in various ways and to varying degrees, the exigency of face masks in the COVID-19 pandemic outweighs the marginal environmental harm.

Along the life cycle stages of a face mask, a number of features could be adapted to streamline the process of mask production, reduce the environmental impact, and improve the fit of masks. Increases in the number of companies producing nonwoven filter media could increase rapid mask production. Advances in biomaterials may allow for masks to be composed of biodegradable polymers [11]. Standardizing tests that measure the filtration efficiency of non-medical masks would better enable consumers to compare different options [18]. Standardizing pressure differential tests of face masks to the same air flow rate (e.g., NIOSH standard of $85 \mathrm{~L} / \mathrm{min}$ ) can allow for easier comparisons between different masks. Mask fit heavily depends on the face shape and size of the wearer, and developing means to measure and optimize fit are important next steps. As new recommendations by the CDC such as those regarding double masking emerge [1], it is important to explore the ability of such modifications to improve mask fit and filtration.

\section{Acknowledgements}

We would like to acknowledge Nicholas Jeffreys, Nishant Sule, the Harvard Face Mask Committee, and the Harvard Active Learning Labs for providing excellent guidance throughout our investigation process. We would especially like to acknowledge Harvard Face Mask Committee members Stephen Blacklow, John Doyle, Willy Shih, Mary Corrigan, Sarah Fortune, and Sara Malconian for their invaluable support and advice. We would also like to recognize Alena Blaise, Jose Gonzalez, Evan Hunsicker, Julia Luehr, Katia Osei, Meghan Turner, and James Young for their contributions during the Harvard SEAS engineering design course. 


\section{Declaration of Competing Interest}

The authors declare no competing interests.

\section{Funding Statement}

This research did not receive any specific grant from funding agencies in the public, commercial, or not-for-profit sectors.

\section{References}

[1] cdc.gov [Internet]. Atlanta: Centers for Disease Control and Prevention; 2020 [cited 2021 February 21]. https://www.cdc.gov/

[2] Godoy LRG, Jones AE, Anderson TN, Fisher CL, Seeley KL, Beeson EA, et al. Facial protection for healthcare workers during pandemics: a scoping review. BMJ Glob Health. 2020 May;5(5):e002553.

[3] Battelle [Internet]. Battelle Memorial Institute; c2017 [cited 2021 Feb 22]. Battelle CCDS.

https://www.battelle.org/inb/battelle-critical-care-decontamination-system-for-covid19

[4] Gilbert RM, Donzanti MJ, Minahan DJ, Shirazi J, Hatem CL, Hayward-Piatkovskyi B, et al. Mask Reuse in the COVID-19 Pandemic: Creating and Inexpensive and Scalable Ultraviolet System for Filtering Facepiece Respirator Decontamination. Glob Health Sci Pract. 2020 Oct 2;8(3):582-595.

[5] Scheid J, Lupien S, Ford G, West S. Commentary: Physiological and psychological impact of face mask usage during the covid-19 pandemic. Int J Environ Res Public Health [Internet]. 2020 Sep 12;17(18). Available from: https:/www.mdpi.com/1660-4601/17/18/6655/htm\#B10-ijerph-17-0665

[6] N95 Face Mask PNG High Quality Image [image]. CC 4.0 BY-NC. Available from: http://www.pngall.com/n95-mask-png/download/44161

[7] The Supply Room. Antimicrobial Cloth Face Mask Black with Matching Ear Straps [photograph]. 2021. Available from: https://www.supplyroom.com/us-military/ppe/. 
[8] Brosseau L, Ann RB. NIOSH Science Blog. [Internet]. N95 respirators and surgical masks. Centers for Disease Control and Prevention. 2009 October 14 [cited 2021 February 20]. Available from: https://blogs.cdc.gov/niosh-science-blog/2009/10/14/n95

[9] O'Dowd K, Nair KM, Forouzandeh P, Mathew S, Grant J, Moran R, et al. Face Masks and Respirators in the Fight against the COVID-19 Pandemic: A Review of Current Materials, Advances and Future Perspectives. Materials [Internet]. 2020 July 29;13(15);3363. Available from: https://doi.org/10.3390/ma13153363

[10] Aragaw, TA. Surgical face masks as a potential source for microplastic pollution in the COVID-19 scenario. Mar Pollut Bull. 2020 Jul 25;159:111517. doi:10.1016/j.marpolbul.2020.111517

[11] Morganti P, Yudin VE, Morganti G, Coltelli MB. Trends in Surgical and Beauty Masks for a Cleaner Environment. Cosmetics. 2020 Aug 31;7:68. doi: 10.3390/cosmetics 7030068

[12] Fadare, OO, Okoffo ED. Covid-19 face masks: A potential source of microplastic fibers in the environment. Sci Total Environ. 2020 Oct 1;737:140279. doi:10.1016/j.scitotenv.2020.140279

[13] Konda A, Prakash A, Moss GA, Schmoldt M, Grant GD, Guha, S. Aerosol Filtration Efficiency of Common Fabrics Used in Respiratory Cloth Masks. ACS Nano. 2020 April 24;14(5):6339-6347.

[14] Chua MH, Cheng W, Goh SS, Kong J, Li B, Lim JY et al. Face Masks in the New COVID-19 Normal: Materials, Testing, and Perspectives. Research. 2020 August 7;2020(7286735):1-40.

[15] Dugdale CM, Walensky RP. Filtration Efficiency, Effectiveness, and Availability of N95 Face Masks for COVID-19 Prevention. JAMA Intern Med. 2020 August 11;180(12):1612-1613.

[16] Fischer EP, Fischer MC, Grass D, Henrion I, Warren WS, Westman E. Low-cost measurement of face mask efficacy for filtering expelled droplets during speech. Sci Adv. 2020 Sep $2 ; 6(36)$. 
[17] Hao W, Parasch A, Williams S, Li J, Ma H, Burken J, Yang W. Filtration performances of non-medical materials as candidates for manufacturing facemasks and respirators. Int $\mathbf{J}$ Hyg Environ Health. 2020 Jul 21;229:113582.

[18] "Standard Specification for Barrier Face Coverings"ASTM F3502-21, ASTM International. DOI:10.1520/F3502-21.

[19] Hossain E, Bhadra S, Jain H, Das S, Bhattacharya A, Ghosh S, Levine D. Recharging and rejuvenation of decontaminated N95 masks. Phys Fluids. 2020 Sept 1;32(9):093304.

[20] Oberg T, Brosseau LM. Surgical mask filter and fit performance. Am J Infect Control. 2008 Jan 31;36(4):276-282.

[21] Hallett S, Toro F, Ashurst JV. Physiology, Tidal Volume. In: StatPearls. Treasure Island (FL): StatPearls Publishing; 2020.

[22] Johns Hopkins Medicine [Internet]. Vital Signs (Body Temperature, Pulse Rate, Respiration Rate, Blood Pressure). c2021 [cited 2020 Sept 25]. Health. Available from: https://www.hopkinsmedicine.org/health/conditions-and-diseases/vital-signs-body-temper ature-pulse-rate-respiration-rate-blood-pressure

[23] Riediker M, Tsai D. Estimation of Viral Aerosol Emissions From Simulated Individuals With Asymptomatic to Moderate Coronavirus Disease 2019. JAMA Netw Open. 2020 Jul 27;3(7):e2013807.

[24] Lee KP, Yip J, Kan CW, Chiou JC, Yung KF. Reusable Face Masks as Alternative for Disposable Medical Masks: Factors that Affect their Wear-Comfort. International Journal of Environmental Research and Public Health. 2020 Sept 18;17(18):6623.

[25] Hu JY, Li Y, Yeung KW. Air permeability. In: Li Y, Wong ASW, editors. Clothing Biosensory Engineering. Cambridge, UK: Woodhead Publishing; 2006. p. 252-260.

[26] Urone PP, Hinrichs R, Dirks K, Sharma M. Viscosity and Laminar Flow. In: College Physics. Texas: OpenStax; 2012. p. 497.

[27] Mahdavi A, Haghighat F, Bahloul A, Brochot C, Ostiguy C. Particle Loading Time and Humidity Effects on the Efficiency of an N95 Filtering Facepiece Respirator Model under Constant and Inhalation Cyclic Flows. Ann Occup Hyg. 2015 Jun;59(5):629-640.

[28] 3M [Internet]. St. Paul: 3M Company; c2021 [cited 2021 Feb 22]. Decontamination of 3M Filtering Facepiece Respirators, such as N95 Respirators, in the United States - 
Considerations.

https://multimedia.3m.com/mws/media/1824869O/decontamination-methods-for-3m-filte ring-facepiece-respirators-technical-bulletin.pdf

[29] Lowe JJ, Paladino KD, Farke JD, Boulter K, Cawcutt K, Emodi M, et al. N95 Filtering Facepiece Respirator Ultraviolet Germicidal Irradiation (UVGI) Process for Decontamination and Reuse. Nebraska Medicine [Internet]. 2020 Apr 10 [cited 2021 Feb 22].

https://www.nebraskamed.com/sites/default/files/documents/covid-19/n-95-decon-proces s.pdf

[30] Ou Q, Pei C, Kim SC, Abell E, Pui DY. Evaluation of decontamination methods for commercial and alternative respirator and mask materials -- view from filtration aspect. J Aerosol Sci. 2020 Dec;150:105609.

[31] Jelden KC, Gibbs SG, Smith PW, Hewlett AL, Iwen PC, Schmid KK, et al. (2016). Comparison of hospital room surface disinfection using a novel ultraviolet germicidal irradiation (UVGI) generator. J Occup Environ Hyg. 2016 Sep;13(9):690-8.

[32] Fischer RJ, Morris DH, van Doremalen N, Sarchette S, Matson MJ, Bushmaker T, et al. Assessment of N95 respirator decontamination and re-use for SARS-CoV-2. medRxiv [Preprint]. 2020 [cited 2021 Feb 22]. https://doi.org/10.1101/2020.04.11.20062018

[33] McDevitt J, Rudnick S, First M, Spengler J. Role of absolute humidity in the inactivation of influenza viruses on stainless steel surfaces at elevated temperatures. Appl Environ Microbiol. 2010 Jun;76(12):3943-7.

[34] COVIDcast [Internet]. Pittsburgh (PA): Carnegie Mellon University Delphi Group. Survey; [cited 2021 Jan 21]. Available from: https://delphi.cmu.edu/covidcast/?sensor=fb-survey-smoothed wearing mask\&level=stat $\underline{\mathrm{e} \& \text { date }}=20210125 \&$ signal $\mathrm{Typ}=$ =value $\&$ mode $=$ overview $\&$ compare $=W I \&$ region $=W I$

[35] He E, Laurent L. Bloomberg Opinion [Internet]. New York City: The World Is Masking Up, Some Are Opting Out; 17 Jul 2020 [cited 2021 January 9]. Available from: https://www.bloomberg.com/graphics/2020-opinion-coronavirus-global-face-mask-adopti on/ 
[36] COVID-19 Projections [Internet]. Seattle(WA): Institute for Health Metrics and Evaluation. Tracker; [cited 2021 Jan 21]. Available from: https://covid19. healthdata.org/united-states-of-america?view=total-deaths\&tab=trend.

[37] YouGov [Internet]. London (U.K.): Personal measures taken to avoid COVID-19; 2018 . Survey; [cited 2021 Jan 21]. Available from:

https://today.yougov.com/topics/international/articles-reports/2020/03/17/personal-measu res-taken-avoid-covid-19

[38] Radar B, White LF, Burns M R, Chen J, Brilliant J, Cohen J, et al. Mask-wearing and control of SARS-CoV-2 transmission in the USA: A cross-sectional study. Lancet Digital Health [Internet]. 2021 Jan 19;3(3). Available from: https://www.thelancet.com/journals/landig/article/PIIS2589-7500(20)30293-4/fulltext

[39] World Covid-19 tracker [Internet]. Atlanta (GA): CNN. Tracker; [cited 2021 Jan 12]. Available from:

https://edition.cnn.com/interactive/2020/health/coronavirus-maps-and-cases/worldmap.ht $\mathrm{ml}$

[40] Hossain MA, Jahid I K, Hossain A, Walton L M, Uddin Z, Haque O, et al. Knowledge, attitudes, and fear of COVID-19 during the Rapid Rise Period in Bangladesh. PLOS ONE [Internet]. 2020 Sep [cited 2021 Jan 21]. Available from: https://journals.plos.org/plosone/article?id=10.1371\%2Fjournal.pone.0239646.

[41] University of Maryland Medical System. Baltimore: University of Maryland Medical System; Wearing a Mask: Myths and Facts. [cited 2021 Jan 29]. Available from: https://www.umms.org/coronavirus/what-to-know/masks/wearing-mask

[42] Rizan C, Reed M, Bhutta MF. Environmental impact of Personal Protective Equipment supplied to health and social care services in England in the first six months of the COVID-19 pandemic. [Internet]. Available from: doi: https://doi.org/10.1101/2020.09.21.20198911

[43] Schmutz M, Hischier R, Batt T, Wick P, Nowack B, Wäger P, Som C. Cotton and Surgical Masks-What Ecological Factors Are Relevant for Their Sustainability? Sustainability. 2020 Dec 8;12:10245. doi: 10.3390/su122410245 
[44] Environmental Protection Agency [Internet]. Greenhouse Gas Emissions from a Typical Passenger Vehicle (n.d.). [cited 2021 February 22]. Available from: https://www.epa.gov/greenvehicles/greenhouse-gas-emissions-typical-passenger-vehicle\# : :text=typical $\% 20$ passenger $\% 20$ vehicle $\% 3 \mathrm{~F}-, \mathrm{A} \% 20$ typical $\% 20$ passenger $\% 20$ vehicle $\% 2$ Demits\%20about $\% 204.6 \% 20$ metric\%20tons $\% 20$ of, $8 \% 2$ C $887 \% 20$ grams $\% 20$ of $\% 20 \mathrm{CO} 2$

[45] The Nature Conservancy [Internet]. (n.d.). Carbon footprint calculator. [cited 2021 February 27]. Available from: https://www.nature.org/en-us/get-involved/how-to-help/carbon-footprint-calculator/

[46] Hoekstra AY, Mekonnen MM. The water footprint of humanity. Proceedings of the National Academy of Sciences. 2012 February 109 (9) 3232-3237. Available from: doi: 10.1073/pnas.1109936109

[47] Hoekstra AY, Chapagain AK. Water footprints of nations: Water use by people as a function of their consumption pattern. Water Resour Manage. 2007 21, 35-48. Available from: https://doi.org/10.1007/s11269-006-9039-x

[48] The World Bank [Internet]. Washington: World Bank Group; c2021 [cited 2021 Feb 26]. Trends in Solid Waste Management. Available from: https://datatopics.worldbank.org/what-a-waste/trends_in_solid_waste_management.html [49] Chu JN, Ghenand O, Collins J, Byrne J, Wentworth A, Chai PR, et al. Thinking Green: Respirator Reuse Strategies to Reduce Cost and Waste. [Preprint]. 2021 [posted 2021 Jan 5; cited 2021 Feb 27]. Available from http://dx.doi.org/10.2139/ssrn.3746257 


\section{Figures}

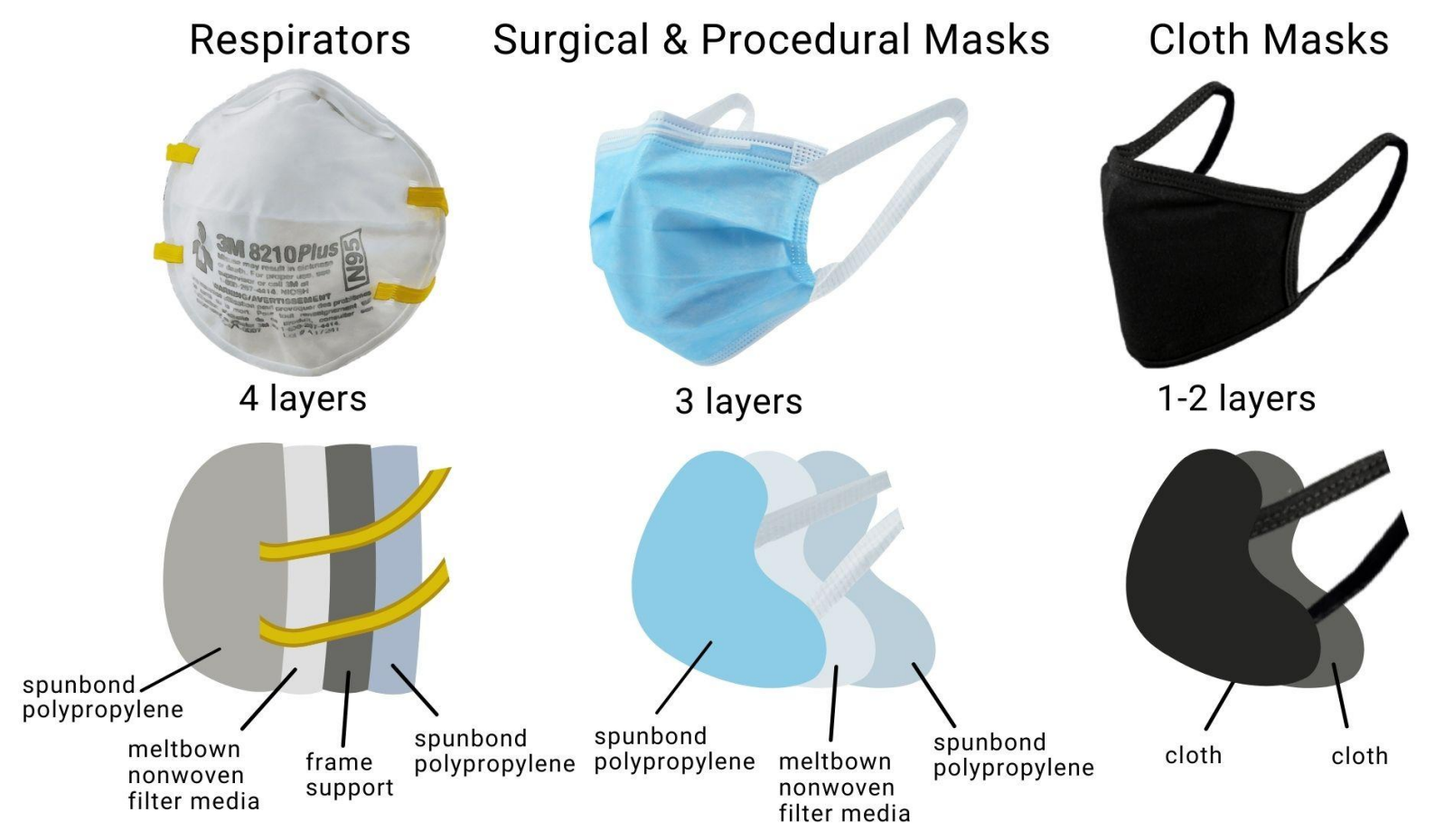

Fig. 1 Images presenting the three main types of face masks, with corresponding depictions of component layers $[6,7]$. 


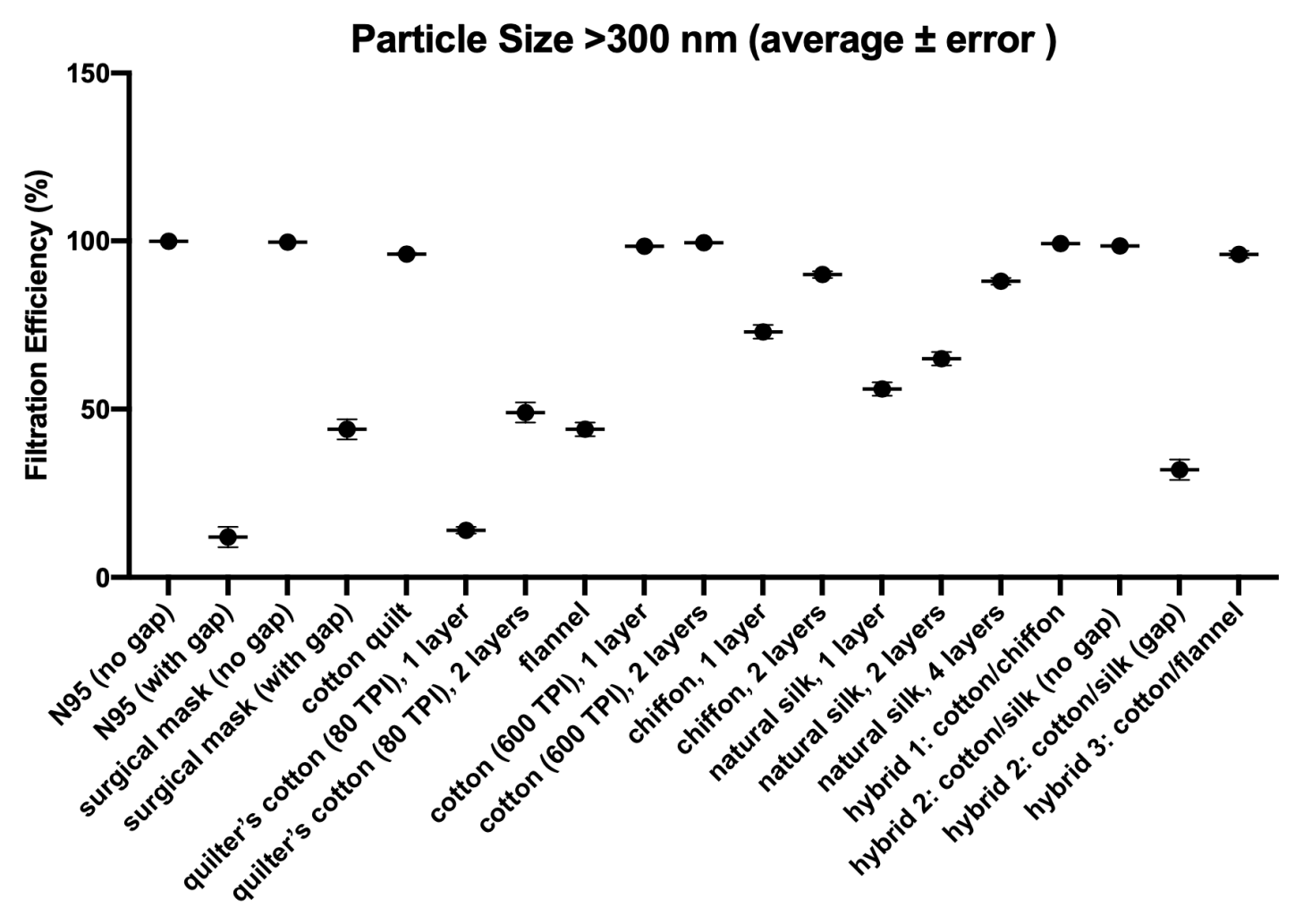

Fig. 2 Filtration efficiencies (\%) of 19 different face masks for $>0.3$ micron particle diameters with a flow rate of $1.2 \mathrm{ft}^{3} / \mathrm{m}$ (data from [13]). 


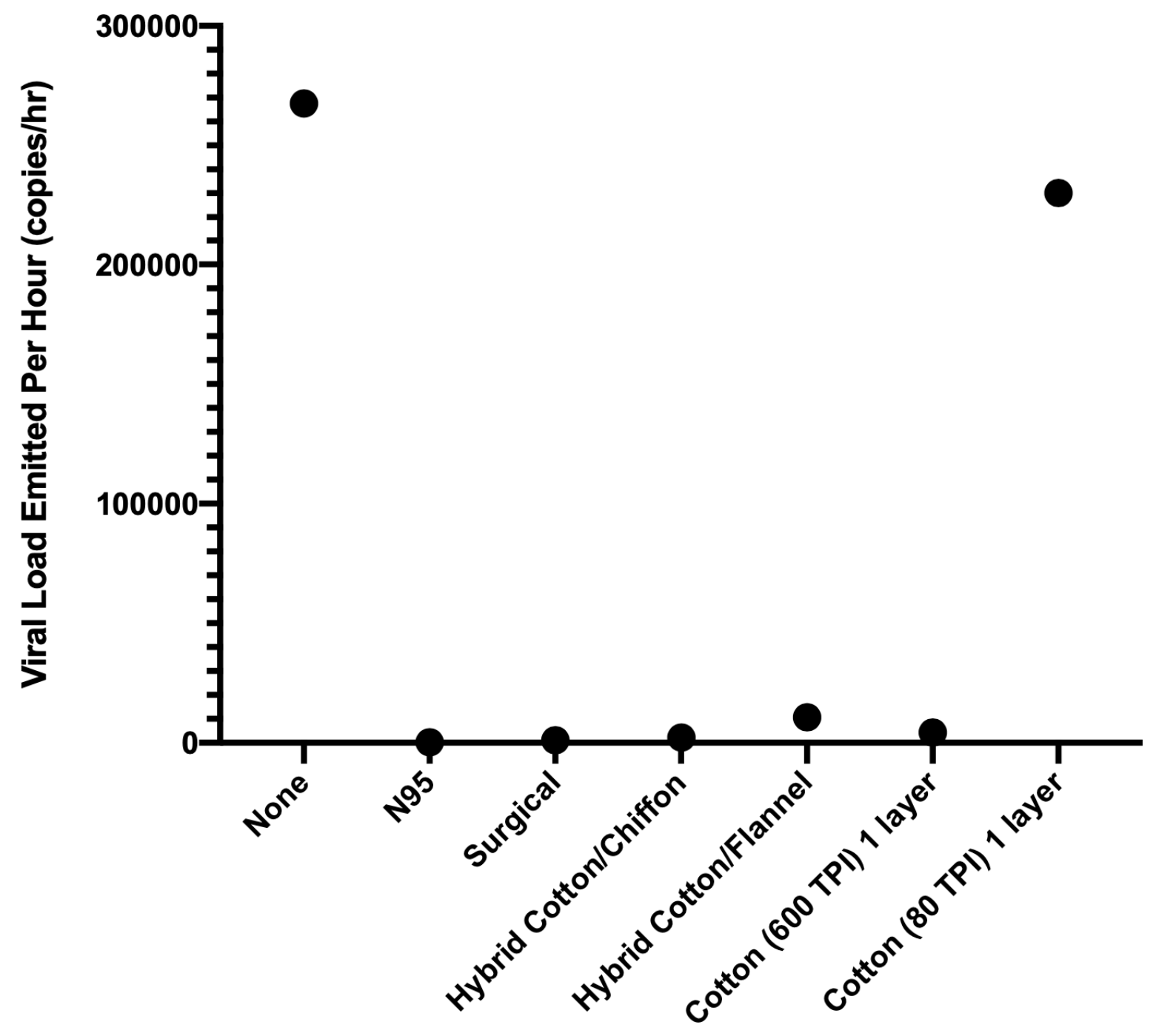

Fig. 3 Estimated viral load emitted per hour in an infected individual breathing normally when not wearing a mask and when wearing 6 different types of masks (calculated using filtration efficiencies from [13]). 


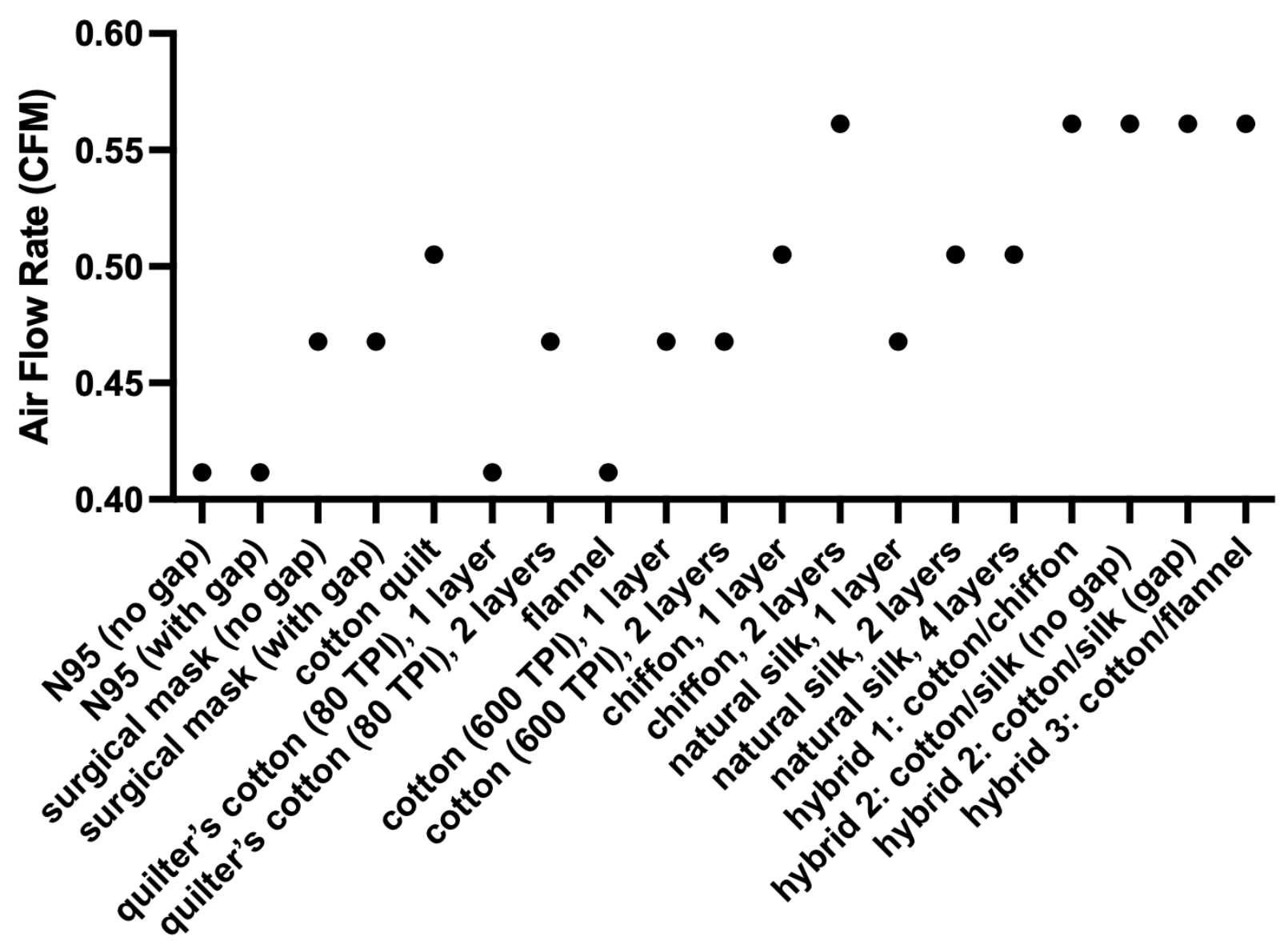

Fig. 4 Required airflow rates in cubic feet per minute (CFM) to transport air at constant radii and pipe lengths (Eq. B) for various masks that exhibit different pressure differentials. Estimate values were calculated using Poiseuille's Law and pressure differential data taken from [13]. 
(A)

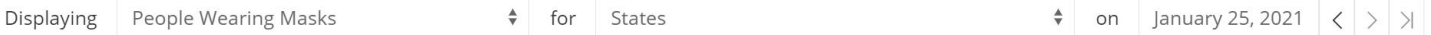

Percentage of people who say they wear a mask most or all of the time while in public, based on surveys of Facebook users
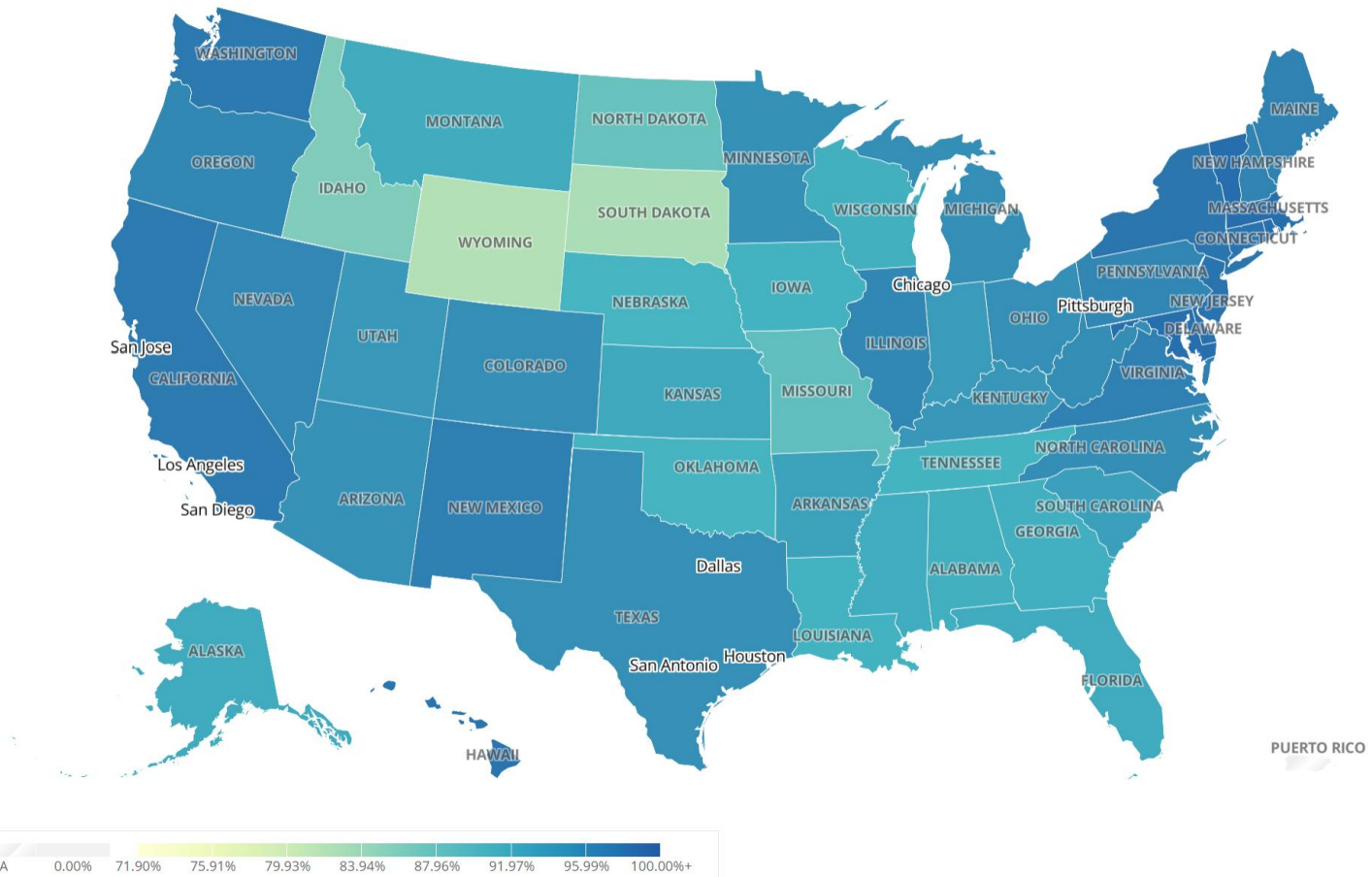

(B)

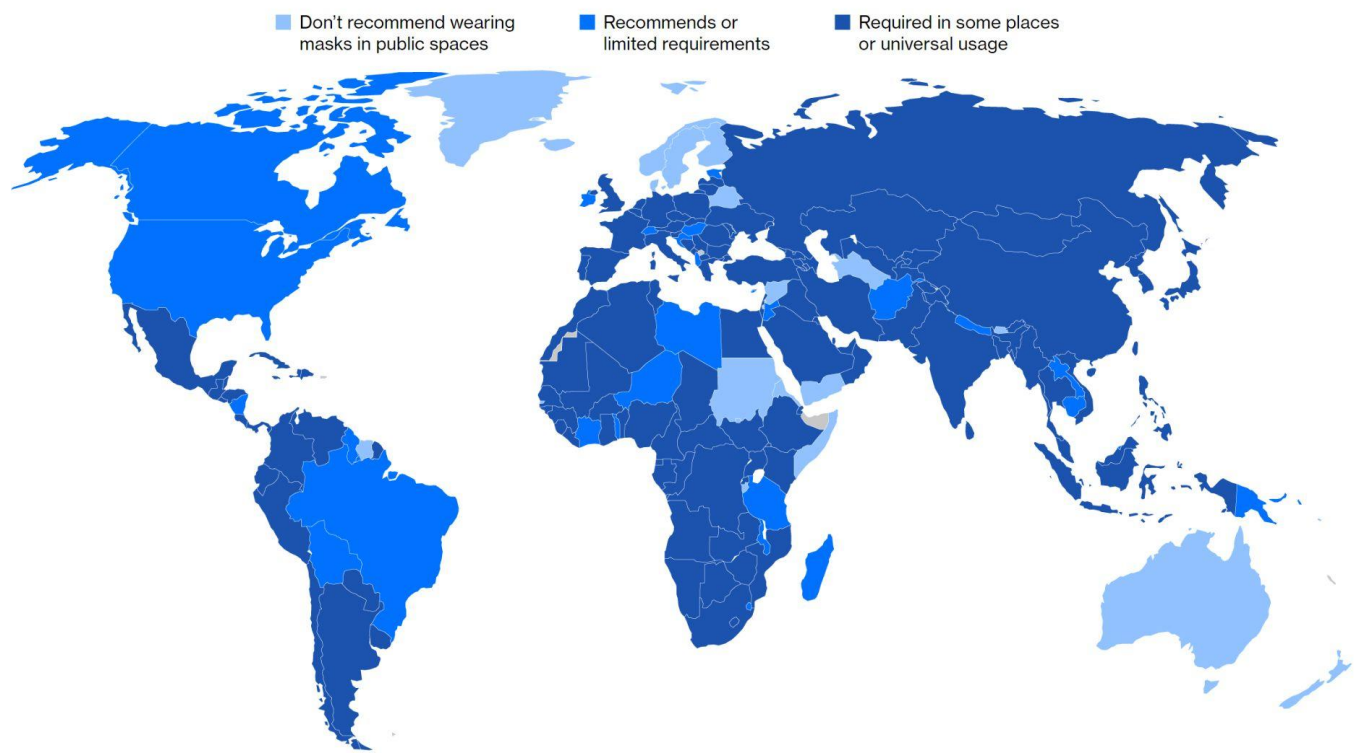

Fig. 5 Public mask usage in the United States and Globally. (A) A daily survey to estimate the percentage of people who say they wear a mask most or all of the time when they are in public 
based on location in the United States as of January 25, 2021 [34]. (B) An image of which countries recommend their citizens to wear masks in public, or which have implemented requirements as of December 2020 [35]. 


\section{Appendix Information}

Table A.1 Cost \& Filtration Efficacy of Different Types of Face Masks.

\begin{tabular}{|l|l|l|l|}
\hline Type of Face Mask* & $\begin{array}{l}\text { Cost (per } \\
\text { mask) }\end{array}$ & $\begin{array}{l}\text { Filtration } \\
\text { Efficiency for } \\
\text { particles <300nm }\end{array}$ & $\begin{array}{l}\text { Filtration } \\
\text { Efficiency for } \\
\text { particles }>\mathbf{3 0 0 n m}\end{array}$ \\
\hline Hybrid 1: Cotton/Chiffon & $\$ 5-10$ & $95-99 \%$ & $100 \%$ \\
\hline Cotton Quilt & $\$ 2-6$ & $94-98 \%$ & $94-97 \%$ \\
\hline Hybrid 3: Cotton/Flannel & & & $92-97 \%$ \\
\hline Hybrid 2a: Cotton/Silk (no gap) & $\$ 10$ & $92-97 \%$ & $94-97 \%$ \\
\hline Natural Silk, 4 layers & $\$ 10-15$ & $80-90 \%$ & $85-90 \%$ \\
\hline N95 & $\$ 1-40$ & $70-100 \%$ & $100 \%$ \\
\hline Chiffon, 2 layers & $\$ 10-18$ & $75-90 \%$ & $90 \%$ \\
\hline Cotton (600 TPI), 2 layers & $\$ 15$ & $62-100 \%$ & $100 \%$ \\
\hline Cotton (600 TPI), 1 layer & $\$ 2-7$ & $55-100 \%$ & $99 \%$ \\
\hline Surgical Mask & $\$ 0.40-\$ 5$ & $50-98 \%$ & $100 \%$ \\
\hline Chiffon, 1 layer & $\$ 15$ & $50-84 \%$ & $75 \%$ \\
\hline Natural Silk, 1 layer & $\$ 15$ & $45-62 \%$ & $55 \%$ \\
\hline Surgical Mask (with gap) & $\$ 0.40-\$ 5$ & $42-58 \%$ & $40-50 \%$ \\
\hline Quilter's Cotton (80 TPI), & $\$ 11$ & $30-50 \%$ & $46-55 \%$ \\
\hline
\end{tabular}




\begin{tabular}{|l|l|l|l|}
\hline layers & & & \\
\hline Hybrid 2b: Cotton/Silk (gap) & $\$ 4.95-15$ & $30-42 \%$ & $30-38 \%$ \\
\hline N95 (with gap) & $\$ 0.50-40$ & $20-50 \%$ & $5-15 \%$ \\
\hline Quilter's Cotton (80 TPI), 1 layer & $\$ 11$ & $0-22 \%$ & $10-15 \%$ \\
\hline
\end{tabular}

*Mask types and filtration efficiencies from [13]

This table highlights the projected cost of an individual face mask. It is important to emphasize that the price for hybrid masks is higher because they are very niche and cannot be bought in bulk at this time. Suppliers for these masks include, but are not limited to, Etsy, Amazon, Target, Walmart, and Ebay.

Eq. A Viral load calculations.

The following calculation estimated the viral load emitted by an infected individual breathing normally at a rate of 14 breaths per minute and not wearing a mask:

Viral load emitted into surroundings per minute $=\frac{14 \text { breaths }}{\mathrm{min}} \times \frac{500 \mathrm{ml}}{\text { breath }} \times \frac{0.637 \text { copies }}{\mathrm{ml}}=4,459 \frac{\text { copies }}{\mathrm{min}}$

Viral load emitted into surroundings per hour $=4,459 \frac{\text { copies }}{\min } \times \frac{60 \mathrm{~min}}{\text { hour }}=267,540 \frac{\text { copies }}{\text { hour }}$

The calculations were then performed for the same infected individual breathing normally only this time while wearing a mask. Equation 2 for bacterial/viral filtration efficiency can be used to calculate the viral load emitted per breath while using a mask. Filtration efficiencies for face masks at particle size $>300 \mathrm{~nm}$ [13] in Figure 3 were used to calculate viral load emitted per breath. Then the same calculations as were performed in the "without mask" case above were repeated using this number to calculate viral load emitted into surrounds per minute and per hour. Below is a general outline of the calculations.

Filtration efficiency $=100\left(\frac{C-F}{C}\right)=100\left(\frac{0.637 \mathrm{copies} / \mathrm{cm}^{3}-F}{0.637 \mathrm{copies} / \mathrm{cm}^{3}}\right) \rightarrow$ solve for $\mathrm{F}$ 
Viral load emitted into surroundings per minute $=\frac{14 \text { breaths }}{\mathrm{min}} \times \frac{500 \mathrm{ml}}{\text { breath }} \times \frac{F \text { copies }}{\mathrm{ml}}$

Viral load emitted into surroundings per hour $=\frac{\text { Viral load emitted into surroundings per minute }}{\text { hour }} \times \frac{60 \text { min }}{\text { hour }}$

Eq. B Air flow calculations.

For design purposes, the system was modeled as a pipe. The assumption was made that the mouth of the wearer of each mask is a circular shape and that there is then a column of air flowing from the mouth through the surface of the mask. Therefore, a cylindrical pipe was assumed to be a reasonable model of this system to gain a rough estimate of the air flow needed across various face masks. Poiseuille's Law (Equation 3) was used to determine these required air flow rates through the different masks, where $Q$ is flow rate, $r$ is radius, $P$ is pressure differential, $L$ is pipe length, and $\eta$ is fluid viscosity.

$$
Q=\pi r^{4} P / 8 \eta L
$$

The diameter of the mouth, and therefore the pipe, was assumed to be roughly $5 \mathrm{~cm}$, and the length of the pipe was assumed to be the thickness of the mask added to the distance from the point of measurement on either side to the mask (i.e. $1 \mathrm{~mm}$ thickness of mask $+2 \mathrm{~cm}$ distance on either side of the mask $=4.1 \mathrm{~cm}$ ). The fluid viscosity was assumed to be roughly the viscosity of air at room temperature (i.e., around $\left.2 * 10^{-5} \frac{\mathrm{kg}}{\mathrm{m}^{*} \mathrm{~s}}\right)[26]$.

Table A.2 Summary of the Effect of VHP Decontamination Methods that have received EUAs on certain 3M Filtering Facepiece Particulate Respirators [28].

\begin{tabular}{|c|c|c|c|c|c|}
\hline $\begin{array}{l}\text { Decontamination } \\
\text { Method }\end{array}$ & $\begin{array}{l}\text { 3M FFR } \\
\text { Models }\end{array}$ & $\begin{array}{l}\text { Number of } \\
\text { Reprocess } \\
\text { Cycles } \\
\text { Tested }\end{array}$ & $\begin{array}{l}\text { Filtration } \\
\text { Efficiency }\end{array}$ & $\begin{array}{l}\text { Fit Related } \\
\text { Evaluation }\end{array}$ & U.S. FDA EUA \\
\hline $\begin{array}{l}\text { VHP: Steris } \\
\text { V-PRO, V-PRO } \\
60\end{array}$ & $\begin{array}{l}1860 \\
1870+\end{array}$ & 10 & Pass & Pass & $\begin{array}{l}\text { EUA (April 9, } \\
\text { 2020) }\end{array}$ \\
\hline
\end{tabular}




\begin{tabular}{|l|l|l|l|l|l|}
\hline & $\begin{array}{l}8210, \\
9205+\end{array}$ & & & & \\
\hline $\begin{array}{l}\text { VHP: ASP, } \\
\text { STERRAD }\end{array}$ & $\begin{array}{l}1860, \\
1860 \mathrm{~S}, \\
8210\end{array}$ & 2 & Pass & Pass & $\begin{array}{l}\text { EUA (April 11, } \\
2020)\end{array}$ \\
\hline VHP: Sterilucent & $\begin{array}{l}1860, \\
1870+, \\
8210\end{array}$ & 10 & Pass & Pass & $\begin{array}{l}\text { EUA (April 20, } \\
\text { 2020) }\end{array}$ \\
\hline VHP: Battelle & $\begin{array}{l}1860, \\
8210, \\
9205+\end{array}$ & 20 & Pass & Pass & $\begin{array}{l}\text { EUA (March } \\
\text { 28, 2020) }\end{array}$ \\
\hline
\end{tabular}

